\title{
Thermal Responsive Shape Memory Polymers for Biomedical Applications
}

\author{
Jianwen $\mathrm{Xu}$ and Jie Song \\ Department of Orthopedics \& Physical Rehabilitation, Department of Cell Biology, \\ University of Massachusetts Medical School, Worcester, \\ USA
}

\section{Introduction}

Shape memory polymers (SMPs) are a type of polymeric materials that can be programmed to memorize a less-constrained shape/configuration, subsequently assume a strained temporary shape/configuration, and then revert to the memorized shape/configuration upon triggering by an external stimulus(Lendlein \& Kelch, 2002). Such responsiveness to stimuli is reminiscent of the adaptive responses universally observed in living organisms. Based on the nature of the external stimulus, SMPs can be categorized into light-responsive SMPs, chemical-responsive SMPs, magnetic field-responsive SMPs, and thermal-responsive SMPs, etc. Thermal-responsive SMPs are one of the most studied systems and will be the focus of this chapter.

Shape memory effect is not a universal property of polymeric materials. Polymer networks comprising of both net-points and reversible switching components, which are responsible for maintaining the dimensional stability and determining reversible thermal response of the polymer, respectively, have the potential to be programmed to exhibit shape memory effect. Processing histories and programming conditions also impact the shape memory effect of an SMP. The intrinsic mechanism for shape memory behavior in thermal responsive SMPs is the reversible freezing and activation of polymeric chain motion in the switching segments below and above the transition temperature $\left(T_{\text {trans }}\right)$, respectively. Shape memory properties have been reported in a wide range of polymers including, but not limited to, polyurethanes, epoxies, polyolefins and polyesters (Behl \& Lendlein, 2007a; Behl, 2010; Lendlein \& Kelch, 2002; Liu, 2007; Mather, 2009).

The earliest report of shape memory effect dated back to the 1940s (Liu, 2007). Industrial applications of the shape memory effect took place in the 1950s when chemist Paul Cook, founder of Raychem Corporation, invented heat shrink tubings using radiation-crosslinked polyethylenes (Dole, 1981). The term "shape memory polymer" became better known as shape memory poly(norborene), developed by the French company CDF-Chimie, was commercialized in Japan by Nippon Zeon Company in the 1980s under the brand name Norsorex. Poly(trans-isoprene) and poly(styrene-butadiene) with shape memory effect were subsequently developed by two other Japanese companies (Leng, 2010). These events ushered in the first golden age of SMP research, which had primarily focused on polyenebased systems until segmental polyurethane-based SMPs were introduced by Mitsubishi 
Heavy Industry (MHI) in the early 1990s (Hayashi, 1995; Ito, 1996; Takahashi, 1996; Tobushi, 1996; Tobushi, 1997; Tobushi, 2001). The flexibility of urethane chemistries enabled the development of shape memory polyurethanes with a wide range of mechanical properties and glass transition temperatures $\left(\mathrm{T}_{\mathrm{g}}\right.$ 's) for individual applications. The publication of a series of landmark papers by Lendlein et al. since 2002 (Lendlein, 2001; Lendlein \& Kelch, 2002; Lendlein \& Langer, 2002), exploring the potential application of SMPs in modern medicine ushered in a second surge in SMP research, with >100 SMP-related patents and research articles published annually (Liu, 2007).

Shape memory polymers as "smart" materials have been extensively reviewed in recent literature (Behl \& Lendlein, 2007a; b; Behl, 2010; Lendlein \& Kelch, 2002; Liu, 2007; Madbouly \& Lendlein, 2010; Mather, 2009; Rousseau, 2008; Sokolowski, 2007; Wagermaier, 2010). This chapter briefly reviews the fundamental principles of thermal responsive SMPs and discusses the challenges of SMPs for biomedical applications. Instead of providing an exhaustive citation of recent literatures, we choose to highlight some key concepts and a few examples revealing the structure-property relationship of SMPs that have inspired our on-going work in this area.

\section{Fundamental principles of SMPs and common characterization techniques}

The driving force for shape recovery of an SMP is the recoiling of polymeric chains from a strained configuration (temporary state) to a less-ordered configuration ("memorized" state), namely, entropy elasticity. The "memorized" state could be the most relaxed, equilibrated configuration as the material was prepared. Upon deformation at a higher temperature ( $\left.\mathrm{T}>\mathrm{T}_{\text {trans }}\right)$, the original orientations of the chain segments are altered and the net-points are dislocated, resulting in new sets of local chain-chain interactions. The temporarily deformed shape can be fixed as the material cools $\left(T<T_{\text {trans }}\right)$, provided that the newly formed chainchain interactions are strong enough to overcome the tendency of the chain segments for elastic recoiling. Upon triggering by a higher temperature $\left(T>T_{\text {trans }}\right)$, the increased entropy of chain segments overcomes the constraining local chain-chain interactions, permitting the recoiling of chain segments to a more disordered state.

The net-points of an SMP network, which maintain its dimensional stability, could be either covalent or physically crosslinked. The switching components that reversibly respond to temperature changes could be either amorphous or semicrystalline. Thus, SMPs could be classified into four main categories (Lendlein \& Kelch, 2002; Liu, 2007; Rousseau, 2008) based on the nature of net-points and switching components: (1) chemically crosslinked net-points with amorphous switching compnents; (2) chemically crosslinked net-points with semicrystalline switching components; (3) physically crosslinked net-points with amorphous switching components; (4) physically crosslinked net-points with semicrystalline switching componetns. According to the polymer classification convention, the first two categories belong to thermosets and the last two belong to thermoplastics, respectively (Gedde, 1995). All four types of SMPs have been realized (Alteheld, 2005; Jeon, 2000; Lendlein, 2001; Ping, 2005). In thermoplastic SMPs, the chain entanglements or local crystalline domains formed by strong chain-chain interactions can serve as the physical crosslinking sites. The advantages of thermoplastic SMPs include their moldability with different permanent shapes/ configurations, high shape deformation range, and the ease for blending with other polymers and additives. On the other hand, the molecular weight of the polymer chains in thermoplastic SMPs need to be sufficiently high in order to enable effective entanglement or distinctive phase separation. Due to the dynamic nature and temperature-dependency of 
these physical crosslinks, the original network points could be destroyed during the deformation with a loss of stored elastic energy, resulting in incomplete shape recovery.

By contrast, thermoset SMPs rarely show creeps (Gedde, 1995). Chemically crosslinked SMPs generally exhibit better strain fixing ratios and strain recovery ratios, faster strain recovery rates and larger shape recovery stress, but lower strain-to-failure values. Such a combination of properties of thermoset SMPs may arise from their higher crosslinking densities and the ability of the chemical crosslinks to better withstand tensile deformations. The main disadvantages of thermoset SMPs are the need for tailored polymer processing and their inability to be reprocessed into a new shape/configuration after being chemically crosslinked, which may not be a concern when the SMP is designed for one time applications, for instance, as in vivo tissue engineering scaffolds.

An ideal SMP system may lie at the interface of thermoplastics and thermosets. Optimization through rational molecular and network designs, combined with the choice of appropriate processing programs, is the key for successful, application-driven design of SMPs.

In essence, the shape memory property is a combination of thermal and mechanical properties. To facilitate subsequent discussions on SMP performances, key terms and techniques used to describe and characterize the shape memory properties of SMPs are defined and summarized below.

Transition temperature ( $\left.T_{\text {trans }}\right)$ is the temperature around which a material changes from one state to another. $T_{\text {trans }}$ could be either melting temperature $\left(T_{m}\right)$ or glass transition temperature $\left(\mathrm{T}_{\mathrm{g}}\right) . \mathrm{T}_{\text {tran }}$ is usually determined by differential scanning calorimetry (DSC), thermomechanical analysis (TMA) or dynamic mechanical thermal analysis (DMA). DSC measures the change in heat capacity, TMA measures the change in coefficient of thermal expansion, while DMA measures the change in elastic modulus during the thermal transition. Due to intrinsic polydispersity in molecular weights and imperfect spatial distribution of network chains, the unique thermal characteristics of a polymer should be defined as a temperature range rather than at one specific temperature. For the ease of comparison, however, a single $\mathrm{T}_{\text {trans }}\left(\mathrm{T}_{\mathrm{m}}\right.$ or $\left.\mathrm{T}_{\mathrm{g}}\right)$ value taken from the peak or midpoint of a broader transition is often reported in literature.

Melting temperature $\left(T_{m}\right)$ is the temperature at which a material changes from solid to liquid state. In polymers, $T_{m}$ is the peak temperature at which a semicrystalline phase melts into an amorphous state. Such a melting process usually takes place within a relative narrow range $\left(<20^{\circ} \mathrm{C}\right)$, thus it is acceptable to report $\mathrm{T}_{\mathrm{m}}$ as a single value.

Glass transition temperature $\left(\mathrm{T}_{\mathrm{g}}\right)$ is the temperature beyond which a polymer turns from a hard, glass-like state to a rubber-like state. For the ease of comparison of conventional polymers, a single $\mathrm{T}_{\mathrm{g}}$ value taken from the midpoint of a broader transition is often used in literature. However, since the width of glass transition have a profound impact on the shape memory performance of SMPs, it will be more appropriate to report the width of the transition along with the mid-point $T_{g}$ value, or to report the onset glass transition temperature $\left(T_{g}\right.$ onset $)$ and the ending glass transition temperature $\left(\mathrm{T}_{\mathrm{g}}\right.$ end $)$ along with the mid-point $\mathrm{T}_{\mathrm{g}}$ value.

Stress ( $\sigma$ ) is defined as the force exerted on the material per area. The ultimate tensile stress that leads to the tensile failure of an SMP, or the ultimate tensile strength, as well as the lowest stress that produces a permanent deformation in an SMP, or the yield strength, are both utilized in the characterization of SMPs.

Strain $(\varepsilon)$ is defined as the deformation per unit length due to stress. The strain-to-failure value indicates the maximum strain that a SMP could reach under external stress.

Modulus (E) is also referred as Young's modulus or elastic modulus. It is the slope of the linear elastic region of a stress-strain curve. E changes significantly with temperature in 
thermal-responsive SMPs. The glassy state modulus of an SMP at a lower temperature can be several orders of magnitude higher than its rubbery state modulus at a higher temperature. The rubbery state modulus of an SMP, indicative of the density of crosslinks, has only minimal influence on the free-strain recovery behavior (e.g. shape recovery rate and shape recover percentage) except when the crosslinking density is extremely low. However, the rubbery state modulus of an SMP dictates the recovery stress during the fixed-strain recovery. The recovery stress is proportional to the energy stored as a deformed SMP is being cooled to fix its temporary shape/configuration. Since the deformation of an SMP usually takes place at its rubbery state, the energy stored could be approximated as the product of its rubbery state modulus and the imposed strain.

Shape fixing components are defined as the domain or net-point, either covalently crosslinked or physically formed (e.g. via physical entanglement or H-bonding), in an SMP network that maintains the dimensional stability during the deformation and subsequent recovery.

Shape switching components are the polymeric chains in an SMP network that can switch from one state to another in response to the temperature change, which are responsible for the temperature-dependent deformation and recovery.

Shape deforming temperature $\left(\mathrm{T}_{\mathrm{d}}\right)$ is the working temperature at which SMP is strained to a temporary shape. The relationship of $\mathrm{T}_{\mathrm{d}}$ relative to $\mathrm{T}_{\text {trans }}$ (below, at or above) has significant impact on the shape memory performance of an SMP.

Temporary shape fixing temperature $\left(\mathrm{T}_{\mathrm{f}}\right)$ is the working temperature at which the temporary shape of a deformed SMP is fixed. $\mathrm{T}_{\mathrm{f}}$ is usually lower than the $\mathrm{T}_{\text {trans. }}$.

Shape recovery temperature $\left(T_{r}\right)$ is the working temperature at which an SMP is triggered to recover from its fixed temporary shape. $T_{r}$ is usually higher than $T_{\text {trans }}$ and is often chosen to be the same as the $T_{d}$.

Cyclic thermo-mechanical test is a widely used quantitative analysis of shape memory performance using a mechanical testing instrument equipped with a temperature control unit (Knight, 2008; Lendlein \& Kelch, 2002; Wagermaier, 2010). The test can be carried out in either stress-controlled or strain-controlled mode. In a stress-controlled cyclic thermomechanical test, a predefined stress and temperature ramping are applied to the SMP and the strain is recorded over time. In a strain-controlled cyclic thermo-mechanical test, a predefined strain and temperature ramping are applied to the SMP and the stress is recorded over time. A typical stress-controlled cyclic thermo-mechanical test in the $\mathrm{N}^{\text {th }}$ cycle constitutes 4 distinctive steps (Fig. 1):

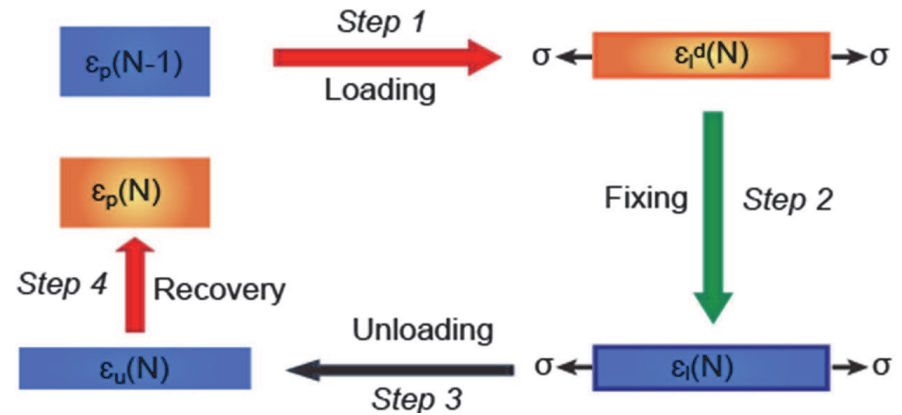

Fig. 1. Programming steps in a stress-controlled cyclic thermo-mechanical test of an SMP. Denotations: $\mathrm{p}=$ permanent, $\mathrm{l}=$ with loading, $\mathrm{d}=$ deformation temperature $\mathrm{T}_{\mathrm{d}}, \mathrm{u}=$ unloading 
Step 1. Equilibrating an SMP with a recorded permanent strain $\varepsilon_{\mathrm{p}}(\mathrm{N}-1)$ at deformation temperature $T_{d}$, followed by subjecting the SMP to predefined deformation stress $\sigma$ at $T_{d}$. The deformed sample length at $T_{d}$ is recorded as $\varepsilon_{1}{ }^{d}(N)$.

Step 2. Fixing the temporary length $\varepsilon_{1}^{d}(N)$ by cooling the SMP to a lower fixing temperature $\left(\mathrm{T}_{\mathrm{f}}\right)$ under constant loading $\sigma$. The recorded fixed strain at $\mathrm{T}_{\mathrm{f}}$ under loading is $\varepsilon_{1}(\mathrm{~N})$.

Step 3. Unloading the stress to zero or a specific lower constrain stress $\left(\sigma_{c}\right)$. The resulting strain after unloading is recorded as $\varepsilon_{u}(N)$.

Step 4. Recovering the shape under either zero stress or a specific constrain stress $\sigma_{c}$ at $T_{r}$. The final recovered strain is recorded as $\varepsilon_{\mathrm{p}}(\mathrm{N})$. In a free-strain recovery mode, the SMP recovers without external constrains either as a function of temperature during a transient heating or as a function of time during an isothermal hold. In the alternative fixed-strain recovery mode, stress is generated within the SMP under full deformation constraint either as a function of temperature during a transient heating or as a function of time during an isothermal hold. Shape recovery stress $\left(E_{r}\right)$, defined as the stress that a SMP exhibits during recovery, could be recorded during this mode.

Shape fixing ratio $\left(\mathbf{R}_{\mathbf{f}}\right)$ is used to evaluate how stably can an SMP be held in a strained temporary shape. It is defined as the ratio of the deformation after unloading versus the deformation at $\mathrm{T}_{\mathrm{f}}$ under the loading $\sigma$, as calculated per Equation (1):

$$
\mathrm{R}_{\mathrm{f}}=\frac{\varepsilon_{\mathrm{u}}(\mathrm{N})-\varepsilon_{\mathrm{p}}(\mathrm{N}-1)}{\varepsilon_{\mathrm{l}}(\mathrm{N})-\varepsilon_{\mathrm{p}}(\mathrm{N}-1)}
$$

Shape recovery ratio $\left(\mathbf{R}_{\mathbf{r}}\right)$ is used to evaluate how completely an SMP recovers to its memorized state (permanent shape). It is defined as the ratio of the recovered deformation at $\mathrm{T}_{\mathrm{r}}$ versus the fixed deformation under stress at $\mathrm{T}_{\mathrm{d}}$, as calculated per Equation (2):

$$
\mathrm{R}_{\mathrm{r}}=\frac{\varepsilon_{\mathrm{u}}(\mathrm{N})-\varepsilon_{\mathrm{p}}(\mathrm{N})}{\varepsilon_{\mathrm{u}}(\mathrm{N})-\varepsilon_{\mathrm{p}}(\mathrm{N}-1)}
$$

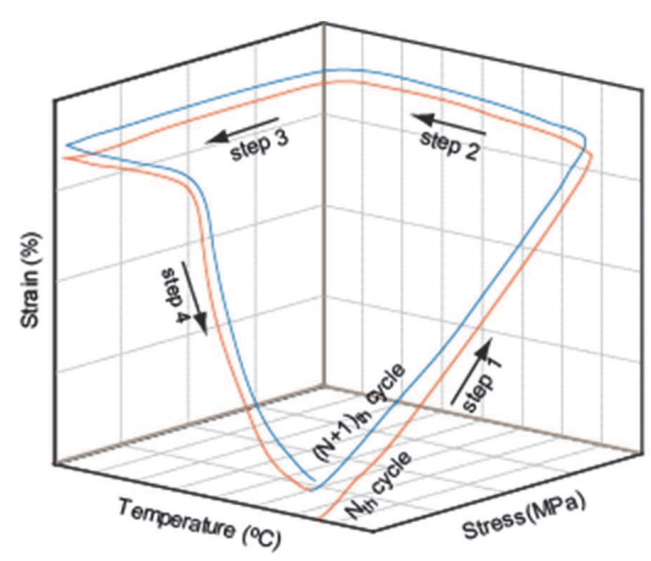

Fig. 2. A representative 3-D plot for presenting cyclic thermo-mechanical testing results. 
Shape recovery time (t) is the time that it takes for an SMP to reach its recoverable strain at $\mathrm{T}_{\mathrm{r}}$. It characterizes how fast an SMP responds to the stimulus. This parameter is mostly reported by studies that video-record real-time shape changes

Cyclic thermo-mechanical testing data are most commonly presented in a three-dimensional (3-D) plot with temperature, stress and strain as $\mathrm{X}, \mathrm{Y}$, and $\mathrm{Z}$ axis (Figure 2), respectively.(Knight, 2008; Lee, 2008; Wagermaier, 2010) Alternatively, the data can be presented in a two-dimension (2-D) graph with multiple $\mathrm{Y}$ axes representing stress, strain and temperature plotting against time on the $X$ axis (Fig.3 ).(Lendlein, 2001; Xie, 2010).

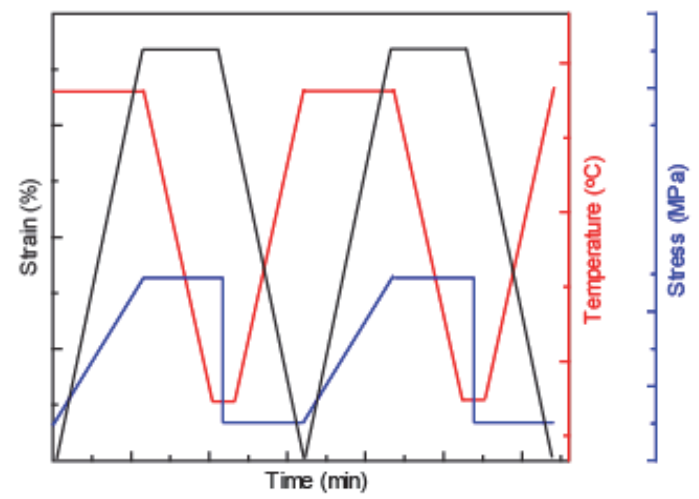

Fig. 3. A representative 2-D plot for presenting cyclic thermo-mechanical testing results. The lines represent a hypothetically ideal SMP with 100\% fixing ratio and and $100 \%$ recovery ratio.

\section{Biomedical SMPs: Applications and challenges}

The unique properties of SMPs present enormous opportunities for the design of nextgeneration less invasive, resorbable smart medical implants, tissue scaffolds and medical devices. Traditional commercial SMPs, including polyurethane-based, polystyrene-based, cyanate ester-based, and epoxy-based SMPs, were not originally designed for biomedical applications. However, as recently reviewed by Sokolowski, Mather, Lendlein and their colleagues (Lendlein, 2010; Mather, 2009; Sokolowski, 2007), a wide range of potential biomedical applications based on SMPs have already emerged or are currently being pursued.

The first SMP-based biomedical application was demonstrated by Hayashi and colleagues who developed SMP-based catheters, which would soften at body temperature, potentially reducing the risks for soft tissue / organ injuries during their surgical delivery (Utsumi, 1995). Maitland et al. designed a thermoset polyurethane SMP-based microactuator for treating strokes (Maitland, 2002; Small, 2007). The microactuator was coupled to an optical fiber and was set in a straight configuration for easy surgical insertion. Upon reaching the targeted blood clot, laser heating was applied to activate the SMP to form a pre-cast corkscrew shape to facilitate the capturing of the thrombus. In order to reach the necessary temperature $\left(65-85^{\circ} \mathrm{C}\right)$ required for actuating the devices, however, significant engineering challenges of the SMP in terms of its optical properties and device geometries had to be met. 
In addition, SMP-based biodegradable self-expanding and drug eluting stents (Wache, 2003; Xue, 2010; Yakacki, 2007), biodegradable self-deployable intragastric implants for treating obesity (Klausner, 2003; Pagano \& Serezin, 2009), self-fitting vascular and coronary grafts (Sokolowski, 2007), patient-specific customized orthopedic devices (Sokolowski, 2007), tissue engineering scaffolds (Cui, 2011; Filion, 2011; Neuss, 2009; Xu \& Song, 2010), and dynamic cell culture substrates (Davis, 2011) have also been explored.

One of the most studied biomedical SMPs is cold hibernated elastic memory (CHEM)processed polyurethane foams for endovascular treatment of aneurysm in animals (Metcalfe, 2003). The pre-compressed CHEM foams were used to occlude aneurysms in dogs as they resumed an expanded, porous configuration, activated by the body heat, to produce near-complete obliteration of aneurysms, resulting in improved angiographic scores in 3 weeks.

Comparing to shape memory alloys (SMAs) that have been broadly used in stents, the SMP counterparts offer the advantages of being lightweight, ease of processing, higher recovery strain, and programmable degradability (El Feninat, 2002). The relatively low recovery stress, slow recovery rate, and the one-way shape memory of most existing SMPs, however, present important yet exciting challenges for the molecular/network design of biocompatible and biodegradable SMPs as high-performance, expandable and resorbable stents.

\section{Recent progress on the network design and shape memory programming of SMPs}

To realize the enormous potential and address the multifaceted challenges of SMPs for biomedical applications, innovative macromolecular designs and network engineering, nanotechnology, and creative shape memory programming techniques have been pursued to improve the shape memory performance within a physiologically relevant temperature range. In this section, we review a few examples that help illustrate how specific properties underlying the fundamental shape memory performance can be improved, followed by an example illustrating how multiple functional requirements may be integrated for biomedical applications.

\subsection{SMP with high recovery stress}

The recovery stress of an SMP positively correlates with the energy stored during its deformation. Most SMPs are deformed in the rubbery state where their typical elastic moduli are in the order of several megapascals $(\mathrm{MPa})$, thus limiting the amount of energy that could be stored and resulting in relatively low shape recovery stress, especially when compared with SMA. A low shape recovery stress could result in incomplete expansive shape recovery within a spatially constraint environment such as a collapsed vertebral disc or a narrowed blood vessel.

To improve the rubbery state elastic modulus, either the crosslinking density of a thermoset SMP or the degree of physical crosslinking in a thermoplastic SMP could be increased. Alternatively, one may improve the rubbery state elastic modulus by incorporating fillers within the SMP network. For instance, SMPs reinforced with SiC particles, carbon powders, carbon nanotubes (CNT), glass fibers or Kevlar fibers showed improved elastic modulus and shape recovery stress but decreased shape recovery percentage (Gall, 2000; Gall, 2002; 
Liu, 2009; Liu, 2004; Madbouly \& Lendlein, 2010). Carbon-based nanoparticles, nanotubes, and nanofiber fillers also introduce electrical conductive properties to the SMPs, enabling potential electrical field-driven triggering. More recently, Miaudet et al. strengthened polyvinyl alcohol (PVA) SMP fibers with a large fraction of CNT (Miaudet, 2007). Significant broadening of the glass transition $\left(\mathrm{T}_{\mathrm{g}}: 50\right.$ to $200{ }^{\circ} \mathrm{C}$ ) was observed for the CNT-PVA fiber versus the neat PVA fiber $\left(\mathrm{T}_{\mathrm{g}}: \sim 80^{\circ} \mathrm{C}\right)$, with much improved storage modulus both at the glassy state and at the rubbery state. When deformed at 70 or $90{ }^{\circ} \mathrm{C}$, the CNT-PVA fiber exhibited a maximal stress of $\sim 150 \mathrm{MPa}$, one to two orders of magnitude greater than the stress generated by conventional SMPs. However, the reinforced CNT-PVA fiber suffered from incomplete shape fixation $\left(\mathrm{R}_{\mathrm{f}}<60 \%\right)$ and no data on the shape recovery time was reported. Another special phenomenon observed in this system was the so-called temperature memory effect, in which the temperature correlating with the peak shape recovery stress during heating was identical to the deformation temperature.

\subsection{Fully recoverable high-strain SMPs}

One of the most important advantages of SMPs over SMAs is their significantly larger deformation strains. Although deformation strains over several hundred percentages have been reported for SMPs, most of these strains could not be fully recovered. The development of SMPs with fully recoverable high-strains will be of significant value to applications requiring dramatic yet complete shape changes.

Thermoplastic SMPs usually exhibit high strain-to-failure but not all of the strains is recoverable. Due to plastic deformation/irreversible damage of physically crosslinked net-points, $R_{r}$ 's of thermoplastic SMPs are usually far less than $100 \%$. By contrast, thermoset SMPs usually have high $\mathrm{R}_{\mathrm{r}}$ 's yet their strain-to-failure tend not to be high. Gall's group proposed that an ideal high-strain SMP may exist at the boundary of a thermoset and a thermoplastic, and should have evenly distributed long chains tethered by light enough crosslinking (Voit, 2010). They systematically studied an acrylate crosslinking system to maximize its fully recoverable strain capacity by adjusting the composition of the co-monomers and crosslinkers. The acrylate network were prepared by crosslinking methyl acrylate (MA), methyl methacrylate (MMA), and isobornyl acrylate (IBoA) with crosslinkers such as poly(ethylene glycol) dimethacrylate (PEGDMA), bisphenol A ethoxylate di(meth)acrylate (BPAEDMA) or a bifunctional crosslinker with both crosslinking and photoinitiating functionalities. SMPs with varied glass transitions and high recoverable strains were obtained. During the optimization of a base polymer composition (19:1/MA:IBoA, wt \%; $0.02 \mathrm{~mol} \%$ initiator) using varied crosslinker BPAEDMA contents, they found that the SMPs with low loading of the crosslinker BPAEDMA $(\leq 0.100 \mathrm{wt} \%)$ were thermoplastic in nature and displayed inconsistent recoverability from high-strain deformations. With the content of BPAEDMA increasing to 0.014 and $0.027 \mathrm{~mol} \%$, the materials could be strained repeatedly to $>800 \%$, although some residual strains of 8 and $5 \%$ could not be fully recovered, respectively. At the BPAEDMA content of $0.054 \mathrm{~mol} \%$, the material still exhibited a fully recoverable high strain-to-failure of $800 \%$. Further increase of BPAEDMA content resulted in the decrease of strain-to-failure. Photoinitiator content and crosslinker length also exerted significant effect on the recovery strain. These data suggested that designing a fully crosslinked network with crosslink spacing that is large and evenly distributed is the key in achieving fully recoverable strain capacity. 


\subsection{SMPs with sharp transition temperatures}

Biomedical SMPs that are designed to thermally deploy (e.g. via catheter heating) in vivo should ideally possess a sharp thermal transition slightly above body temperature. Such a thermal property is important to prevent premature shape recovery as the SMP is being delivered in a minimally invasive configuration to its targeted location at body temperature and to minimize potential cellular and tissue damage when it is subsequently triggered to deploy.

For both chemically and physically crosslinked SMPs, the shape switching segments could be either crystalline or amorphous. The width of thermal transition of an SMP is dependent on the distribution of relaxation time associated with the molecular mobility of polymer chains, which in turn is dictated by the chemical composition and network structure of the SMP. Crystalline segments usually exhibit a sharp transition with a relatively narrow temperature range while amorphous segments tend to display a glass transition range tens of degrees wide. The maximum shape recovery rate seems to increase with the narrowing of glass transitions.

A broad transition temperature range has dual effects on the shape memory properties. One may take advantage of the broad transition range to program multi-stage shape memory effects or temperature memory effects, or to enable higher shape recovery stress on one end. For instance, it was shown that when deformation was carried out at a temperature lower than the $T_{g}$ in an epoxy thermoset, it resulted in a lower shape recovery temperature and higher shape recovery stress (Gall, 2005; Liu, 2004).

On the other hand, a broad transition temperature could also have negative impact on the shape memory performance, for instance, resulting in less stable/incomplete shape fixing, premature shape recovery, and/or slower shape recovery. For SMPs with narrow $\mathrm{T}_{\text {trans }}$ windows, fixing a temporary shape at a temperature $20{ }^{\circ} \mathrm{C}$ below the $\mathrm{T}_{\text {trans }}$ and triggering the shape recovery at a temperature $20{ }^{\circ} \mathrm{C}$ above the $\mathrm{T}_{\text {trans }}$ are usually adequate in achieving good shape fixing and recovery. For SMPs with broad transition windows, however, some percentages of the switching segments would still remain mobile at $20{ }^{\circ} \mathrm{C}$ below the $\mathrm{T}_{\text {trans, }}$ and some switching components may start to recover prematurely at a temperature far below its $\mathrm{T}_{\text {trans. }}$. For example, $20 \%$ of the shape recovery of a poly(MMAco-PEGDA)-based SMP took place at a temperature at as low as $>40{ }^{\circ} \mathrm{C}$ below its $\mathrm{T}_{\mathrm{g}}$ of $92{ }^{\circ} \mathrm{C}$ (Yakacki, 2008). These disadvantages could cause problems for biomedical applications where an SMP implant needs to be delivered in a stably held minimally invasive configuration and remain so until a safe temperature triggers its rapid deployment. Premature deployment at an unintended in vivo location could have grave consequences to the patient.

Predictable shape recovery is conventionally considered more obtainable by SMPs with crystalline switching segments. However, recent work shows that it is possible to design SMP networks with amorphous switching segments to display glass transitions as narrow as $10{ }^{\circ} \mathrm{C}$. The key is to keep the chain segments between netpoints as identical as possible, which can be accomplished by crosslinking well-defined star-branched macromers. For instance, Nagahama et al. prepared biodegradable polyurethane SMPs by crosslinking 8-arm star-branched poly( $\varepsilon$-caprolactone) (PCL) macromers, containing 10 or 20 PCL repeating units per arm, with hexamethylene diisocyanate (Nagahama, 2009). The resulting SMPs both showed outstanding strain fixing ratio $\left(\mathrm{R}_{\mathrm{f}}>97 \%\right)$ and strain recovery ratio $(\mathrm{Rr} \approx 100 \%)$. The SMP crosslinked from macromers containing longer PCL arms 
displayed complete shape recovery within a $6{ }^{\circ} \mathrm{C}$ range $\left(47-53{ }^{\circ} \mathrm{C}\right)$ that correlated well with its $\mathrm{T}_{\mathrm{m}}$ of $49{ }^{\circ} \mathrm{C}$. Interestingly, the SMP crosslinked from macromers containing shorted PCL arms exhibited a more temperature-sensitive recovery, accomplishing $90 \%$ strain recovery within a $2{ }^{\circ} \mathrm{C}$ heating window $\left(37-39{ }^{\circ} \mathrm{C}\right)$ that was below its $\mathrm{T}_{\mathrm{m}}$ of $43{ }^{\circ} \mathrm{C}$ and $100 \%$ recovery in $10 \mathrm{~s}$ at the $\mathrm{T}_{\mathrm{m}}$.

Nair et al. recently reported homogenous SMP networks prepared by thiol-ene photopolymerization that exhibited glass transitions as narrow as $12{ }^{\circ} \mathrm{C}$ (Nair, 2010). By tuning the network compositions, two thiol-ene SMPs with $\mathrm{T}_{\mathrm{g}}$ 's around $30-40{ }^{\circ} \mathrm{C}$ were obtained. These materials exhibited excellent shape fixing at room temperature, distinct shape memory actuation response, and a rapid shape recovery rate $(5 \% / \mathrm{min}$ versus the $1.8-4.2 \% / \mathrm{min}$ commonly observed with other SMPs).

\subsection{SMPs with multi-shape memory effect}

It's generally accepted that the number of shapes an SMP can memorize correlates with the number of discrete reversible phase transitions within its network. Conventional SMPs are designed to memorize only one permanent shape that corresponds to the most relaxed state of the switching segments, exhibiting the so-called dual-shape memory effect. The first example of triple-shape memory effect was reported by Bellin et al. where two types of polymeric chains with discrete transition temperatures were incorporated within a crosslinked network (Bellin, 2006). One of the polymer networks containing poly(e-caprolactone) (PCL) segments and poly(cyclohexyl methacrylate) (PCHMA) segments, named MACL, exhibited a $\mathrm{T}_{\mathrm{m}}$ around $50{ }^{\circ} \mathrm{C}$ and a $\mathrm{T}_{\mathrm{g}}$ around $140{ }^{\circ} \mathrm{C}$. The second network containing PCL segments and poly(oligomer polyethylene glycol monomethyl ether methacrylate) (PPEGMA), named CLEG, exhibited two $\mathrm{T}_{\mathrm{m}}$ 's above $50{ }^{\circ} \mathrm{C}$ and around 17-39 ${ }^{\circ} \mathrm{C}$ depending on the content of PPEGMA. For shape memory programming, a sample adopting a shape $C$ was deformed to shape $B$ at a temperature $\left(T_{\text {high }}\right)$ above the higher one of the two $\mathrm{T}_{\text {trans }} \mathrm{s}$, and then shape $\mathrm{B}$ was fixed by cooling the sample to a temperature $\left(\mathrm{T}_{\mathrm{mid}}\right)$ between the two $T_{\text {trans }}$ 's before it was further deformed into shape $A$ at $T_{\text {mid }}$ and fixed by cooling below the lower temperature of the two $\mathrm{T}_{\text {trans }} \mathrm{s}$. During the shape recovery, the sample was heated above $T_{\text {high }}$ where shape $B$ and Shape $C$ were recovered sequentially. Both MACL and CLEG engineered with appropriate compositions were able to display such a triple-shape memory effect. It's noteworthy that the deformed shapes B and A were not necessarily unidirectional, which opens the opportunity for applications where complex and multi-directional shape recovery is required. Tuning the triple-shape memory effect in these systems, however, required fine adjustments of the ratio of the two discrete phases. For example, the triple-shape memory effect was only observed for the MACL networks at PCL content of 40-60 wt \% and for the CLEG networks at PCL content of 30-60 wt \%. It was also found that $R_{f}$ increased with increasing content of the component forming the domain responsible for the transition. In addition, low $R_{\mathrm{f}}$ 's were observed during the programming. In the case of the MACL network, the shape fixing ratio of $B$ following deformation from $C$ was relatively poor $\left(R_{f}=48 \%\right.$ to $\left.87 \%\right)$, likely due to the fact that polymeric chains exhibiting the higher $T_{\text {trans }}$ and those exhibiting the lower $T_{\text {trans }}$ could both be affected during this delicate programming step.

Using a different approach, Xie et al. realized triple shape memory effect in a crosslinked macroscopic polymer bilayers with two well separated phase transitions (Xie, 2009). The bilayer SMPs were fabricated by curing an epoxy polymer layer L exhibiting a lower 
$\mathrm{T}_{\mathrm{g}}\left(38^{\circ} \mathrm{C}\right)$ on top of another pre-formed epoxy polymer layer $\mathrm{H}$ exhibiting a higher $\mathrm{T}_{\mathrm{g}}\left(78{ }^{\circ} \mathrm{C}\right)$. A similar programming process as described above was used to program the triple-shape memory effect. Similarly, poor $R_{\mathrm{f}}$ 's were observed after the first deformationfixing cycle. Strong interfacial bonding between the two macroscopic layers was found to be critical for accomplishing the triple shape memory effect using this approach. Because of the generalizability of this method, it may be extended for the fabrication of multiple-shape memory effect in an SMP consisting of more than two macroscopic layers.

More recently, Xie designed a unique SMP system with multiple-shape memory effect using a single neat polymer, perfluorosulphonic acid ionomer (PFSA) (Xie, 2010). PFSA is a commercial thermoplastic with a polytetrafluoroethylene backbone and perfluoroether sulfonic acid side chains (Fig. 4a). It has a broad glass transition over $55-130{ }^{\circ} \mathrm{C}$ (Fig. $4 \mathrm{~b}$ ) corresponding to the short-range segmental motions within the electrostatic network. PFSA exhibits dual shape memory effect with excellent $R_{f}$ and $R_{r}(\sim 100 \%)$ regardless whether the employed $T_{d}$ and $T_{r}$ are at the onset, the mid-point, or the ending of the glass transition window. However, it was found that the deformation strain introduced at a higher $T_{d}$ could not be recovered fully with a lower $\mathrm{T}_{\mathrm{r}}$, and a well-defined multi-stage recovery was observed when the sample was heated in a staged manner (Fig. 5). Deformation temperature memory effect was also observed in PFSA. Such a phenomenon was also observed in a strengthened PVA SMP (Voit, 2010), although no multiple-shape memory effect was reported. A broad glass transition such as the one in PFSA could be viewed as a collection of an infinite numbers of sharp transitions. At a given $\mathrm{T}_{\mathrm{d}}$ or $\mathrm{T}_{\mathrm{f}}$, only a portion of the collective transitions was activated or frozen, resulting in the multi-stage shape memory behaviors. Such a phenomenon is also expected in other amorphous or semicrystalline SMPs with broad reversible thermal transitions, which could serve as a more feasible approach to engineer SMPs with multi-shape memory effects.

a

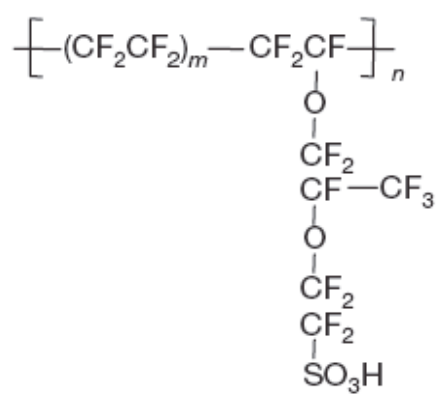

b

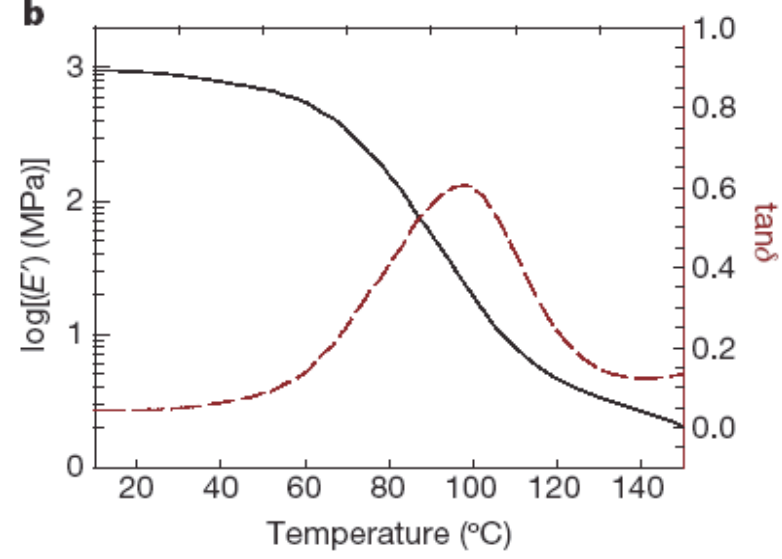

Fig. 4. Structure and dynamic mechanical properties of PFSA. a, Structure of PFSA, b, Dynamic mechanical analysis curve of PFSA. (Adapted with permission from (Xie, 2010). 2010. Nature Publishing Group Inc.) 


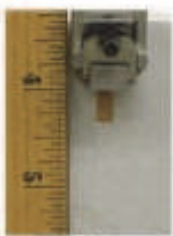

SO

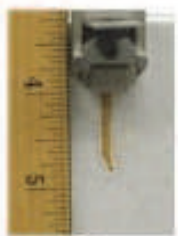

S1

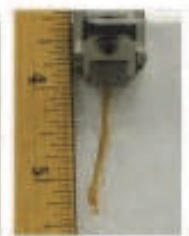

S2

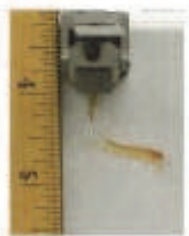

S3

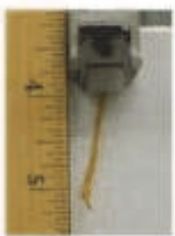

$\mathrm{S} 2_{\text {rec }}$

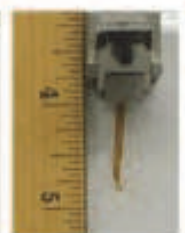

$\mathrm{S} 1_{\text {rec }}$

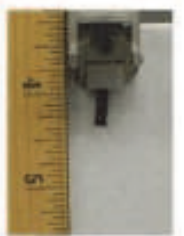

$\mathrm{SO}_{\text {rec }}$

Fig. 5. Quadruple-shape memory properties of PFSA. S0: permanent shape; S1: first temporary shape $\left(\mathrm{T}_{\mathrm{d}} 1: 140{ }^{\circ} \mathrm{C}\right)$; $\mathrm{S} 2$ : second temporary shape $\left(\mathrm{T}_{\mathrm{d}^{2}}: 107^{\circ} \mathrm{C}\right)$; $\mathrm{S} 3$ : third temporary shape $\left(\mathrm{T}_{\mathrm{d}}{ }^{3}: 68^{\circ} \mathrm{C}\right) ; \mathrm{S} 2_{\text {rec }}$ recovered second temporary shape $\left(\mathrm{T}_{\mathrm{r}} 1: 68^{\circ} \mathrm{C}\right) ; \mathrm{S} 1_{\text {rec }}$ : recovered first temporary shape $\left(\mathrm{T}_{\mathrm{r}} 2: 107^{\circ} \mathrm{C}\right)$; $\mathrm{S}_{\mathrm{rec}}$ : recovered permanent shape $\left(\mathrm{T}_{\mathrm{r}}{ }^{3}: 140{ }^{\circ} \mathrm{C}\right)$. (Adapted with permission from (Xie, 2010). 2010. Nature Publishing Group Inc.)

\subsection{SMPs with multiple functional properties}

As discussed in Section 2, in vivo applications of SMPs often require that multiple factors governing the efficiency and safety of their clinical use be considered. Combining adequate mechanical properties, efficient shape memory effects, suitable degradability and biofunctionality in one material design is challenging yet necessary for biomedical SMPs. For example, we envision that a "smart" SMP bone substitute may be fabricated with a permanent configuration that precisely matches with a patient's defect configuration (e.g. guided by X-rays or MRI scans). Such a SMP scaffold can be deformed into a minimally invasive shape to facilitate its surgical insertion. Once reaching its targeted location, the scaffold can then be thermally triggered to conform to the defect to provide the necessary supportive functions, structurally and/or mechanically. The scaffold should also be ideally resorbable as it induces new bone ingrowth. For such an application, the SMP network needs to exhibit adequate mechanical strength at body temperature, both before and after the thermal deployment, and should have the ability to rapidly and completely recover at a physiological safe triggering temperature. Finally, such an SMP should also have tunable degradation rates potentially matching with new bone ingrowth rate.

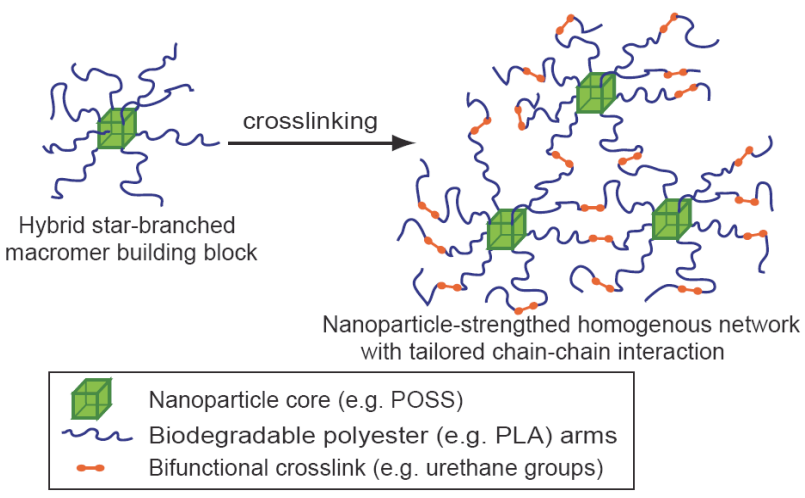

Fig. 6. Depiction of a multi-functional SMP network. (Adapted with permission from $(\mathrm{Xu} \&$ Song, 2010). 2010, the National Academy of Sciences, USA.) 
To achieve complete freezing of chain segment motion below $\mathrm{T}_{\text {trans }}$ (temporary shape fixation) and full activation of all chain segments above $\mathrm{T}_{\text {trans }}$ (shape recovery), a homogenous SMP network consisting of identical chains with tunable chain-chain interactions would be ideal. We recently demonstrated that a network crosslinked from well-defined star-branched macromer containing bulky rigid core could meet such requirements (Fig. 6) (Xu \& Song, 2010). The bulky, rigid, symmetric core was designed to define the spatial distribution of polyester arms and decrease excessive chain-chain interactions upon crosslinking. The multiple reactive ends of the macromer were designed to achieve adequate mechanical strength via high-density crosslinking and desired bioactivity via selective end-group functionalization. By using the strategy of crosslinking of pre-formed macromers, a wide range of chemistries could be applied for preparing welldefined macromer with tunable chemical compositions and thus degradation profiles.

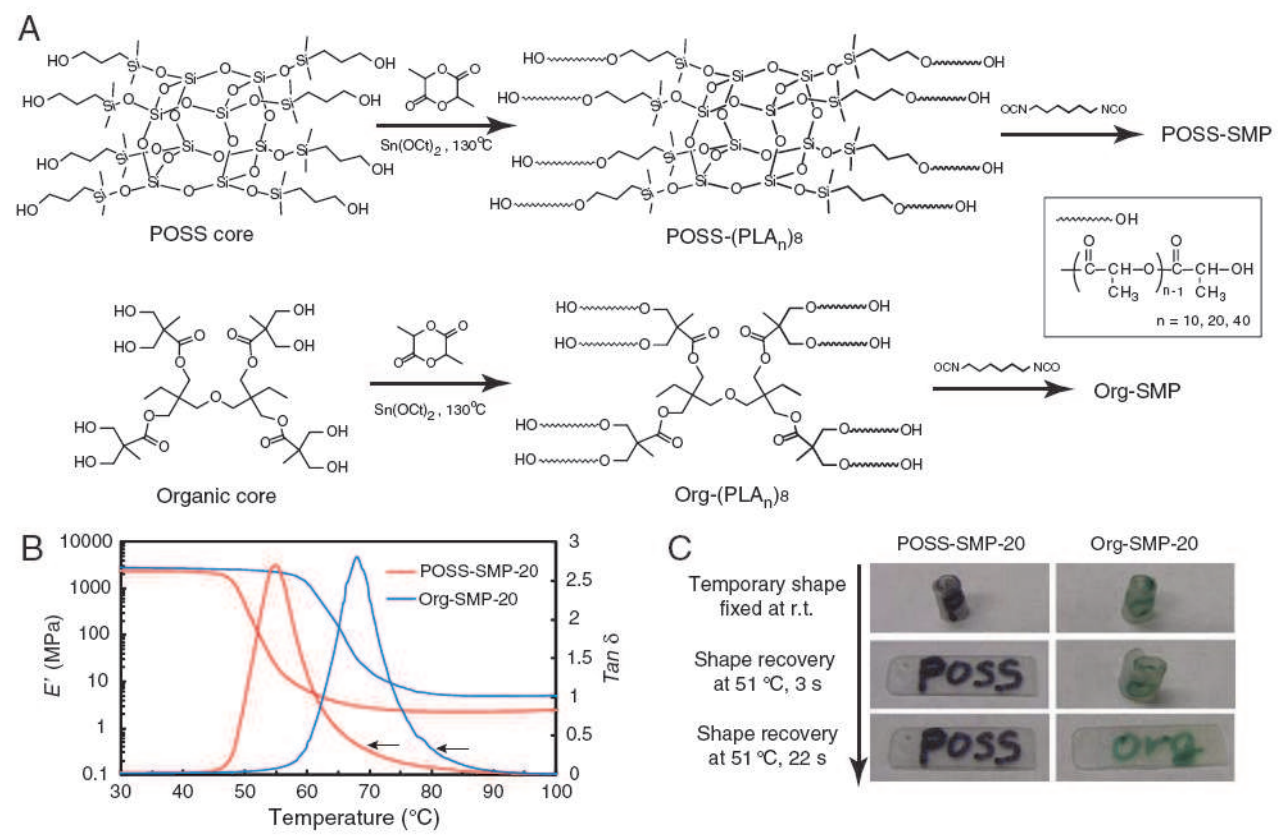

Fig. 7. Preparation and thermal mechanical properties of SMPs containing POSS (POSS$\mathrm{SMP}$ ) vs. organic (Org-SMP) anchors: (A) synthesis and crosslinking of macromers; (B) Storage modulus ( $\left.\mathrm{E}^{\prime}\right)$-temperature and loss angle (Tan $\delta$ )-temperature (denoted by black arrows) curves of POSS-SMP-20 vs. Org-SMP-20; (C) Recovery rates of POSS-SMP-20 (red arrows) vs. Org-SMP-20 (blue arrows) from an identical rolled-up temporary shape (left panel) to fully extended rectangle $(30.0 \mathrm{~mm} \times 6.0 \mathrm{~mm} \times 0.5 \mathrm{~mm})$ in water at $51^{\circ} \mathrm{C}$. (Adapted with permission from (Xu \& Song, 2010). 2010, the National Academy of Sciences, USA.)

Specifically, we designed a nanoparticle-mediated homogeneous SMP network that exhibited an extraordinary combination of stable temporary shape fixation and rapid and full shape recovery around physiological temperature with excellent mechanical 
properties (Xu \& Song, 2010). Cubic polyhedral oligomeric silsesquioxane (POSS) was chosen as the core nanoparticle and POSS-centered, 8-arm polyester macromer, (POSS$\left(\mathrm{PLA}_{\mathrm{n}}\right)_{8}(\mathrm{n}=10,20,40)$, were pre-synthesized by ring-opening polymerization of $\mathrm{D}, \mathrm{L}-$ lactide (Fig. 7A). Upon crosslinking by diisocyanates, a POSS-modulated SMP network (POSS-SMP) was formed. A control network (Org-SMP) crosslinked from a less bulky and more flexible all-organic macromer, $\left(\operatorname{Org}-\left(\mathrm{PLA}_{n}\right)_{8}(\mathrm{n}=10,20,40)\right.$, were also prepared to facilitate a comparative study of the role of the core structure on the thermal mechanical properties of the SMP network.

The unique capability of the bulky and symmetric POSS core in modulating spatial distribution and interaction of chains enabled the formation of a highly crosslinked POSSSMP network with homogenous and less entangled microstructure. Although POSS-SMP and Org-SMP possessed the same crosslinking density and equally narrow glass transitions, POSS-SMP had significantly lower $\mathrm{T}_{\mathrm{g}}$ than its Org-SMP counterpart (Fig. 7B). The effect of POSS core on the interaction of polymeric arms within the nanostructured molecular network also translated, on a macroscopic scale, into more rapid shape recovery at a lower triggering temperature. For example, shape memory performance testing demonstrated that both POSS-SMP-20 and Org-SMP-20 could be stably fixed at a temporary shape within seconds upon cooling to room temperature, indicating complete freezing of chain segment motions below the $\mathrm{T}_{\mathrm{g}}$ in both networks. At $51^{\circ} \mathrm{C}$, the rate of shape recovery of POSS-SMP-20 $(<3 \mathrm{~s})$ was much faster than that of Org-SMP-20 (>20 s) (Fig. 7C), although they both recovered at a similar rate $(<1 \mathrm{~s})$ at $73{ }^{\circ} \mathrm{C}$.

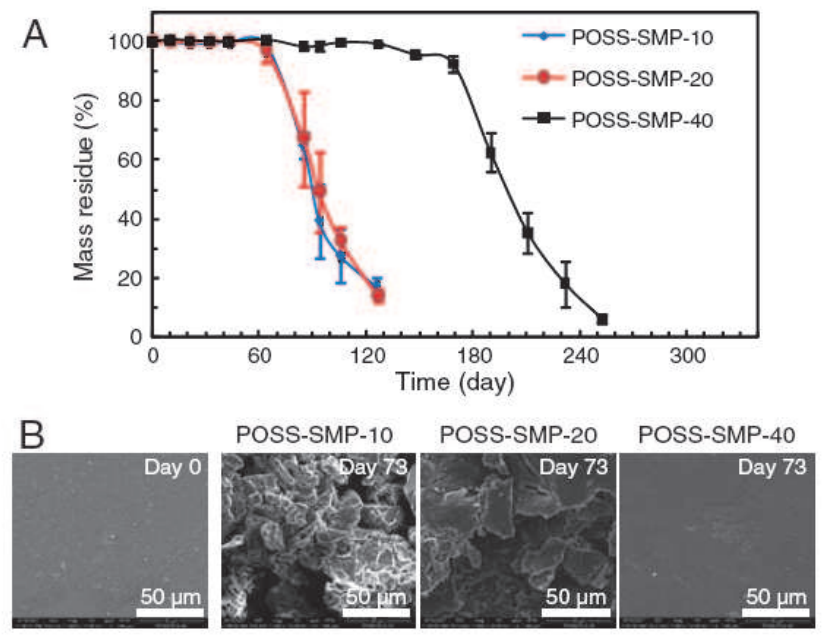

Fig. 8. In vitro hydrolytic degradation of POSS-SMPs: (A) \%Mass residue of POSS-SMPs in PBS ( $\mathrm{pH}$ 7.4) as a function of time and PLA arm length. A sample size of 3 was applied. (B) SEM micrographs of POSS-SMPs before and after 73-day incubation in PBS at $37^{\circ} \mathrm{C}$. (Adapted with permission from (Xu \& Song, 2010). 2010, the National Academy of Sciences, USA.)

The effect of the POSS core on the thermal mechanical properties of the SMP network was further exemplified by the glass transition change as a function of PLA chain length. In contrast to Org-SMPs where the $\mathrm{T}_{\mathrm{g}}$ 's decreased with the increase of chain length as a result 
of lower crosslinking density, the $\mathrm{T}_{\mathrm{g}}$ 's in POSS-SMPs increased from $42.8^{\circ} \mathrm{C}$ at $\mathrm{n}=10$ to 48.4 ${ }^{\circ} \mathrm{C}$ at $\mathrm{n}=40$. The storage modulus of POSS-SMPs and Org-SMPs at the rubbery state both decreased with the increase of PLA chain length $n$, consistent with the expected lower crosslinking densities at longer inter-netpoint chain lengths.

All POSS-SMPs $(n=10,20$, and 40$)$ exhibited a $T_{g}$ slightly above body temperature $\left(\sim 50{ }^{\circ} \mathrm{C}\right)$. Equally important, they all exhibited an extremely narrow glass transition range, with peak widths at the half peak height $(\mathrm{WHPH})$ less than $10^{\circ} \mathrm{C}$, accompanied by sharp storage modulus changes of up to 3 orders of magnitude around the glass transitions. By contrast, most conventional SMP networks exhibit wide glass transitions (WHPH $>20^{\circ} \mathrm{C}$ ) with no more than 2 orders of magnitude modulus change around the $\mathrm{T}_{\text {trans. }}$ Such a narrow glass transition endowed POSS-SMPs with excellent shape fixing at body temperature, which was slightly below their $\mathrm{T}_{\mathrm{g}}$ 's, and instant recovery at a safe triggering temperature slightly above their $\mathrm{T}_{\mathrm{g}}$ 's. Indeed, we showed that all POSS-SMPs exhibited stable temporary shape fixing at room temperature for $>1$ year, instant and complete recovery around $50{ }^{\circ} \mathrm{C}$, and over 2-GPa storage modulus at body temperature. These properties combined make the POSS-SMPs uniquely suited for weight-bearing in vivo applications, for instance, as self-fitting bone tissue engineering scaffolds that can be delivered in a minimally invasive fashion to an area of defect and subsequently deployed to conform to the defect.

Moreover, we demonstrated that the degradability of POSS-SMPs could be tuned by the lengths of the PLA arms of the presynthesized macromers (Figure 8). The POSS-SMPs with shorter PLA arms degraded much faster than those with longer PLA arms. The tunable degradation profiles make it possible to make customized scaffold according to the tissue healing rate. Moreover, the multiple $-\mathrm{OH}$ end-groups on the macromer provide extra anchors for further attachment of bioactive molecules, as demonstrated by the covalent coupling of fluorescently tagged RGD peptide using "click" chemistry. Finally, using a rat subcutaneous implantation model, we showed that POSS-SMPs were minimally immunogenic and did not elicit pathologic abnormities in any vital/scavenger organs one year after implantation (Filion, 2011).

\section{Conclusion}

In summary, despite significant progress on the macromolecular engineering, network formation strategies, shape memory programming / processing techniques in SMPs, the development of SMPs suitable for biomedical applications remains to be a challenging topic. Each SMP system we discussed above has its unique advantages and disadvantages, and provides valuable hints to an integrated solution to the design of biomedical SMPs.

\section{Acknowledgements}

This work was supported by the National Institutes of Health grants R01AR055615 and R01GM088678.

\section{References}

Alteheld A, Feng YK, Kelch S \& Lendlein A. (2005).Biodegradable, amorphous copolyesterurethane networks having shape-memory properties. Angewandte Chemie-International Edition; Vol.44, No.8, pp. 1188-1192, ISSN 1433-7851 
Behl M \& Lendlein A. (2007a).Shape-memory polymers. Materials Today; Vol.10, No.4, pp. 2028, ISSN 1369-7021

Behl M \& Lendlein A. (2007b).Actively moving polymers. Soft Matter; Vol.3, No.1, pp. 58-67, ISSN 1744-683X

Behl M, Razzaq MY \& Lendlein A. (2010).Multifunctional Shape-Memory Polymers. Advanced Materials; Vol.22, No.31, pp. 3388-3410, ISSN 0935-9648

Bellin I, Kelch S, Langer R \& Lendlein A. (2006).Polymeric triple-shape materials. Proceedings of the National Academy of Sciences of the United States of America; Vol.103, No.48, pp. 18043-18047, ISSN 0027-8424

Cui J, Kratz K, Heuchel M, Hiebl B \& Lendlein A. (2011).Mechanically active scaffolds from radio-opaque shape-memory polymer-based composites. Polymers for Advanced Technologies; Vol.22, No.1, pp. 180-189, ISSN 1042-7147

Davis KA, Burke KA, Mather PT \& Henderson JH. (2011).Dynamic cell behavior on shape memory polymer substrates. Biomaterials; Vol.32, No.9, pp. 2285-2293, ISSN 01429612

Dole M. (1981).History of the Irradiation Cross-Linking of Polyethylene. Journal of Macromolecular Science-Chemistry; Vol.A 15, No.7, pp. 1403-1409, ISSN 0022-233X

El Feninat F, Laroche G, Fiset M \& Mantovani D. (2002).Shape memory materials for biomedical applications. Advanced Engineering Materials; Vol.4, No.3, pp. 91-104, ISSN 1438-1656

Filion TM, Xu JW, Prasad ML \& Song J. (2011).In vivo tissue responses to thermal-responsive shape memory polymer nanocomposites. Biomaterials; Vol.32, No.4, pp. 985-991, ISSN 0142-9612

Gall K, Mikulas M, Munshi NA, Beavers F \& Tupper M. (2000).Carbon fiber reinforced shape memory polymer composites. Journal of Intelligent Material Systems and Structures; Vol.11, No.11, pp. 877-886, ISSN 1045-389X

Gall K, Dunn ML, Liu YP, Finch D, Lake M \& Munshi NA. (2002).Shape memory polymer nanocomposites. Acta Materialia; Vol.50, No.20, pp. 5115-5126, ISSN 1359-6454

Gall K, Yakacki CM, Liu YP, Shandas R, Willett N \& Anseth KS. (2005).Thermomechanics of the shape memory effect in polymers for biomedical applications. Journal of Biomedical Materials Research Part A; Vol.73A, No.3, pp. 339-348, ISSN 1549-3296

Gedde UW. (1995). Polymer Physics, Kluwer Academic Publishers, ISBN 0412626403,

Hayashi S, Kondo S, Kapadia P \& Ushioda E. (1995).Room-Temperature-Functional ShapeMemory Polymers. Plastics Engineering; Vol.51, No.2, pp. 29-31, ISSN 0091-9578

Ito K, Abe K, Li HL, Ujihira Y, Ishikawa N \& Hayashi S. (1996).Variation of free volume size and content of shape memory polymer polyurethane upon temperature studied by positron annihilation lifetime techniques and infrared spectroscopy. Journal of Radioanalytical and Nuclear Chemistry-Articles; Vol.211, No.1, pp. 53-60, ISSN 02365731

Jeon HG, Mather PT \& Haddad TS. (2000).Shape memory and nanostructure in poly(norbornyl-POSS) copolymers. Polymer International; Vol.49, No.5, pp. 453-457, ISSN 0959-8103

Klausner EA, Lavy E, Friedman M \& Hoffman A. (2003).Expandable gastroretentive dosage forms. Journal of Controlled Release; Vol.90, No.2, pp. 143-162, ISSN 0168-3659

Knight PT, Lee KM, Qin H \& Mather PT. (2008).Biodegradable thermoplastic polyurethanes incorporating polyhedral oligosilsesquioxane. Biomacromolecules; Vol.9, No.9, pp. 2458-2467, ISSN 1525-7797

Lee KM, Knight PT, Chung T \& Mather PT. (2008).Polycaprolactone-POSS chemical/physical double networks. Macromolecules; Vol.41, No.13, pp.4730-4738, ISSN 0024-9297 
Lendlein A, Schmidt AM \& Langer R. (2001).AB-polymer networks based on oligo(epsiloncaprolactone) segments showing shape-memory properties. Proceedings of the National Academy of Sciences of the United States of America; Vol.98, No.3, pp. 842-847, ISSN 0027-8424

Lendlein A \& Kelch S. (2002).Shape-memory polymers. Angewandte Chemie-International Edition; Vol.41, No.12, pp. 2034-2057, ISSN 1433-7851

Lendlein A \& Langer R. (2002).Biodegradable, elastic shape-memory polymers for potential biomedical applications. Science; Vol.296, No.5573, pp. 1673-1676, ISSN 0036-8075

Lendlein A, Behl M, Hiebl B \& Wischke C. (2010).Shape-memory polymers as a technology platform for biomedical applications. Expert Review of Medical Devices; Vol.7, No.3, pp. 357-379, ISSN 1743-4440

Leng J, (Ed). (2010). Shape-Memory Polymers and Multifunctional Composites, CRC Press, ISBN 9781420090192

Liu C, Qin H \& Mather PT. (2007).Review of progress in shape-memory polymers. Journal of Materials Chemistry; Vol.17, No.16, pp. 1543-1558, ISSN 0959-9428

Liu YJ, Lv HB, Lan X, Leng JS \& Du SY. (2009).Review of electro-active shape-memory polymer composite. Composites Science and Technology; Vol.69, No.13, pp. 2064-2068, ISSN 0266-3538

Liu YP, Gall K, Dunn ML \& McCluskey P. (2004).Thermomechanics of shape memory polymer nanocomposites. Mechanics of Materials; Vol.36, No.10, pp. 929-940, ISSN 0167-6636

Madbouly SA \& Lendlein A. (2010).Shape-Memory Polymer Composites. Shape-Memory Polymers; Vol.226, pp. 41-95, ISSN 0065-3195

Maitland DJ, Metzger MF, Schumann D, Lee A \& Wilson TS. (2002).Photothermal properties of shape memory polymer micro-actuators for treating stroke. Lasers in Surgery and Medicine; Vol.30, No.1, pp. 1-11, ISSN 0196-8092

Mather PT, Luo XF \& Rousseau IA. (2009).Shape Memory Polymer Research. Annual Review of Materials Research; Vol.39, pp. 445-471, ISSN 1531-7331

Metcalfe A, Desfaits AC, Salazkin I, Yahia L, Sokolowski WM \& Raymond J. (2003).Cold hibernated elastic memory foams for endovascular interventions. Biomaterials; Vol.24, No.3, pp. 491-497, ISSN 0142-9612

Miaudet P, Derre A, Maugey M, Zakri C, Piccione PM, Inoubli R \& Poulin P. (2007).Shape and temperature memory of nanocomposites with broadened glass transition. Science; Vol.318, No.5854, pp. 1294-1296, ISSN 0036-8075

Nagahama K, Ueda Y, Ouchi T \& Ohya Y. (2009).Biodegradable Shape-Memory Polymers Exhibiting Sharp Thermal Transitions and Controlled Drug Release. Biomacromolecules; Vol.10, No.7, pp. 1789-1794, ISSN 1525-7797

Nair DP, Cramer NB, Scott TF, Bowman CN \& Shandas R. (2010).Photopolymerized thiol-ene systems as shape memory polymers. Polymer; Vol.51, No.19, pp. 4383-4389, ISSN 0032-3861

Neuss S, Blomenkamp I, Stainforth R, Boltersdorf D, Jansen M, Butz N, Perez-Bouza A \& Knuchel R. (2009). The use of a shape-memory poly(is an element ofcaprolactone)dimethacrylate network as a tissue engineering scaffold. Biomaterials; Vol.30, No.9, pp. 1697-1705, ISSN 0142-9612

Pagano P \& Serezin DR, inventors; Compagnie Europeenne d'Elude et de Dispositifs pour L'Implantation par Laparoscopie (Vienne, FR) assignee. Shape memory intragastric balloon. France patent 2009/0093838. 20092009.

Ping P, Wang WS, Chen XS \& Jing XB. (2005).Poly(epsilon-caprolactone) polyurethane and its shape-memory property. Biomacromolecules; Vol.6, No.2, pp. 587-592, ISSN 1525-7797 
Rousseau IA. (2008). Challenges of Shape Memory Polymers: A Review of the Progress Toward Overcoming SMP's Limitations. Polymer Engineering and Science; Vol.48, No.11, pp. 2075-2089, ISSN 0032-3888

Small W, Wilson TS, Buckley PR, Benett WJ, Loge JA, Hartman J \& Maitland DJ. (2007).Prototype fabrication and preliminary in vitro testing of a shape memory endovascular thrombectomy device. Ieee Transactions on Biomedical Engineering; Vol.54, No.9, pp. 1657-1666, ISSN 0018-9294

Sokolowski W, Metcalfe A, Hayashi S, Yahia L \& Raymond J. (2007).Medical applications of shape memory polymers. Biomedical Materials; Vol.2, No.1, pp. S23-S27, ISSN 1748-6041

Takahashi T, Hayashi N \& Hayashi S. (1996).Structure and properties of shape-memory polyurethane block copolymers. Journal of Applied Polymer Science; Vol.60, No.7, pp. 1061-1069, ISSN 0021-8995

Tobushi H, Hara H, Yamada E \& Hayashi S. (1996).Thermomechanical properties in a thin film of shape memory polymer of polyurethane series. Smart Materials \& Structures; Vol.5, No.4, pp. 483-491, ISSN 0964-1726

Tobushi H, Hashimoto T, Hayashi S \& Yamada E. (1997).Thermomechanical constitutive modeling in shape memory polymer of polyurethane series. Journal of Intelligent Material Systems and Structures; Vol.8, No.8, pp. 711-718, ISSN 1045-389X

Tobushi H, Okumura K, Endo M \& Hayashi S. (2001).Thermomechanical properties of polyurethane shape-memory polymer foam. Shape Memory Materials and Its Applications; Vol.394-3, pp. 577-580, ISSN 0255-5476

Utsumi A, Morita Y, Kaide T, Onishi K \& Hayashi S, inventors; Mitsubishi Cable Indudtries, Ltd., Amagasaki

Mitsubishi Jukogyo Kabushiki Kaisha, Tokyo, assignee. Catheter with body temperature glass transtion region. Japan patent 5441489. 1995 Aug. 15, 1995.

Voit W, Ware T, Dasari RR, Smith P, Danz L, Simon D, Barlow S, Marder SR \& Gall K. (2010).High-Strain Shape-Memory Polymers. Advanced Functional Materials; Vol.20, No.1, pp. 162-171, ISSN 1616-301X

Wache HM, Tartakowska DJ, Hentrich A \& Wagner MH. (2003).Development of a polymer stent with shape memory effect as a drug delivery system. Journal of Materials ScienceMaterials in Medicine; Vol.14, No.2, pp. 109-112, ISSN 0957-4530

Wagermaier W, Kratz K, Heuchel M \& Lendlein A. (2010).Characterization Methods for ShapeMemory Polymers. Shape-Memory Polymers; Vol.226, pp. 97-145, ISSN 0065-3195

Xie T, Xiao XC \& Cheng YT. (2009).Revealing Triple-Shape Memory Effect by Polymer Bilayers. Macromolecular Rapid Communications; Vol.30, No.21, pp. 1823-1827, ISSN 1022-1336

Xie T. (2010).Tunable polymer multi-shape memory effect. Nature; Vol.464, No.7286, pp. 267270, ISSN 0028-0836

Xu JW \& Song J. (2010).High performance shape memory polymer networks based on rigid nanoparticle cores. Proceedings of the National Academy of Sciences of the United States of America; Vol.107, No.17, pp. 7652-7657, ISSN 0027-8424

Xue LA, Dai SY \& Li Z. (2010).Biodegradable shape-memory block co-polymers for fast selfexpandable stents. Biomaterials; Vol.31, No.32, pp. 8132-8140, ISSN 0142-9612

Yakacki CM, Shandas R, Lanning C, Rech B, Eckstein A \& Gall K. (2007).Unconstrained recovery characterization of shape-memory polymer networks for cardiovascular applications. Biomaterials; Vol.28, No.14, pp. 2255-2263, ISSN 0142-9612

Yakacki CM, Shandas R, Safranski D, Ortega AM, Sassaman K \& Gall K. (2008).Strong, tailored, biocompatible shape-memory polymer networks. Advanced Functional Materials; Vol.18, No.16, pp. 2428-2435, ISSN 1616-301X 


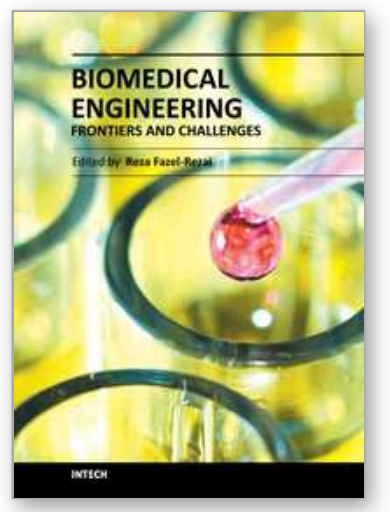

\author{
Biomedical Engineering - Frontiers and Challenges \\ Edited by Prof. Reza Fazel
}

ISBN 978-953-307-309-5

Hard cover, 374 pages

Publisher InTech

Published online 01, August, 2011

Published in print edition August, 2011

In all different areas in biomedical engineering, the ultimate objectives in research and education are to improve the quality life, reduce the impact of disease on the everyday life of individuals, and provide an appropriate infrastructure to promote and enhance the interaction of biomedical engineering researchers. This book is prepared in two volumes to introduce recent advances in different areas of biomedical engineering such as biomaterials, cellular engineering, biomedical devices, nanotechnology, and biomechanics. It is hoped that both of the volumes will bring more awareness about the biomedical engineering field and help in completing or establishing new research areas in biomedical engineering.

\title{
How to reference
}

In order to correctly reference this scholarly work, feel free to copy and paste the following:

Jianwen Xu and Jie Song (2011). Thermal Responsive Shape Memory Polymers for Biomedical Applications, Biomedical Engineering - Frontiers and Challenges, Prof. Reza Fazel (Ed.), ISBN: 978-953-307-309-5, InTech, Available from: http://www.intechopen.com/books/biomedical-engineering-frontiers-and-challenges/thermalresponsive-shape-memory-polymers-for-biomedical-applications

\section{INTECH}

open science | open minds

\section{InTech Europe}

University Campus STeP Ri Slavka Krautzeka 83/A 51000 Rijeka, Croatia

Phone: +385 (51) 770447

Fax: +385 (51) 686166 www.intechopen.com

\section{InTech China}

Unit 405, Office Block, Hotel Equatorial Shanghai No.65, Yan An Road (West), Shanghai, 200040, China 中国上海市延安西路65号上海国际贵都大饭店办公楼405单元 Phone: +86-21-62489820

Fax: +86-21-62489821 
(C) 2011 The Author(s). Licensee IntechOpen. This chapter is distributed under the terms of the Creative Commons Attribution-NonCommercialShareAlike-3.0 License, which permits use, distribution and reproduction for non-commercial purposes, provided the original is properly cited and derivative works building on this content are distributed under the same license. 